\title{
Desempenho das organizações de produtores rurais do estado do Ceará na implementação dos mecanismos de gestão social
}

Durante os últimos anos no Brasil se desenvolveram um conjunto de políticas, programas e projetos públicos direcionados para a inserção social, econômica e política de segmentos sociais mais fragilizados do campo. Muitas destas políticas abordaram e abordam a temática do desenvolvimento rural compreendendo componentes essenciais no processo: valorização e fortalecimento da agricultura familiar, diversificação econômica nos territórios, incentivo e incremento do empreendedorismo local. Neste sentido, o Governo do Estado do Ceará vem consolidando experiência na coordenação e execução de programas e projetos, dentre eles o Projeto de Desenvolvimento Rural Sustentável - PDRS conhecido como Projeto São José III. Enquanto política pública teve como objetivo realizar investimentos produtivos para organização de produtores da agricultura familiar com foco na geração de renda no campo e fortalecimento da gestão organizativa. O presente artigo tem por objetivo analisar o desempenho da gestão das organizações de agricultores familiares por meio da mensuração do índice de Gestão Social. A concepção de gestão social foi a da organização social e da ac, a o coletivizada, isto e', a organização de diferentes atores que se encontram imbricados na gestão social. Os dados utilizados são de origem primária, obtidos por meio da aplicação de 52 questionários estruturados para organizações beneficiárias (Tratados) e não beneficiárias (Controle) situadas em 11 territórios rurais do Estado do Ceará. O mesmo questionário foi aplicado antes e depois da intervenção do Projeto, para ambos os grupos. Os testes aplicados revelaram que não existe diferença significativa entre as organizações beneficiadas e não beneficiadas pelo Projeto e que as organizações apresentam níveis relativamente baixos de gestão social apontando fragilidades. Não foi constatada mudança significativa nesse cenário durante o período 2014 a 2017.

\section{Performance of organizations of rural producers in the state of Ceará in the implementation of social management mechanisms}

\begin{abstract}
During the last few years in Brazil a set of public policies, programs and projects have been developed aimed at the social, economic and political insertion of the most fragile social segments in the field. Many of these policies addressed and address the theme of rural development, comprising essential components in the process: valuing and strengthening family farming, economic diversification in the territories, incentives and increasing local entrepreneurship. In this sense, the Government of the State of Ceará has been consolidating experience in the coordination and execution of programs and projects, including the Sustainable Rural Development Project - PDRS known as the São José III Project. As a public policy, it aimed to make productive investments for the organization of family farming producers with a focus on generating income in the countryside and strengthening organizational management. This article productive investments for the organization of family farming producers with a focus on generating income in the countryside and strengthening organizational management. This article
aims to analyze the management performance of family farmers' organizations by measuring the Social Management Index. The concept of social management was that of social organization aims to analyze the management performance of family farmers' organizations by measuring the Social Management Index. The concept of social management was that of social organization
and collectivized action, that is, the organization of different actors who are intertwined in social management. The data used are of primary origin, obtained through the application of 52 structured questionnaires for beneficiary (Treaties) and non-beneficiary (Control) organizations located in 11 rural territories in the State of Ceará. The same questionnaire was applied before and after the intervention of the Project, for both groups. The applied tests revealed that there is no significant difference between the organizations benefited and not benefited by the Project and that the organizations present relatively low levels of social management pointing out weaknesses. There was no significant change in this scenario during the period 2014 to 2017
\end{abstract}

Keywords: Rural Development; Family farming; Organization of family farmers and Management.

Topic: Planejamento, Gestão e Políticas Públicas Ambientais

Reviewed anonymously in the process of blind peer.

Ana Karina Cavalcante Holanda (iD

Universidade Federal do Ceará, Brasil

http://lattes.cnpq.br/8927084586217629

http://orcid.org/0000-0003-0118-8036

karinaholanda@hotmail.com

Ahmad Saaed Khan (1D)

Universidade Federal do Ceará, Brasil

http://lattes.cnpq.br/3198350508846033

http://orcid.org/0000-0002-4079-7574

saaed@ufc.br

Patrícia Verônica Pinheiro Sales Lima Universidade Federal do Ceará, Brasil http://lattes.cnpq.br/7172491133426747

http://orcid.org/0000-0002-6622-3640

pvpslima@ufc.br
Received: 10/12/2019

Approved: 21/01/2020

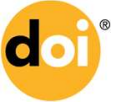

DOI: $10.6008 / C B P C 2179-6858.2020 .001 .0038$
Referencing this:

HOLANDA, A. K. C.; KHAN, A. S.; LIMA, P. V. P. S.. Desempenho das organizações de produtores rurais do estado do Ceará na implementação dos mecanismos de gestão social. Revista Ibero Americana de Ciências Ambientais, v.11, n.1, p.429-444, 2020. DOI: http://doi.org/10.6008/CBPC2179-6858.2020.001.0038 


\section{INTRODUÇÃO}

Durante os últimos anos no Brasil se desenvolveram um conjunto de políticas, programas e projetos públicos direcionados para a inserção social, econômica e política de segmentos sociais mais fragilizados do campo. No entanto, esse esforço ainda é insuficiente, o que se pode observar analisando os indicadores tradicionais do nível de desenvolvimento alcançados em todas as regiões do país, mas com maior dramaticidade nas regiões Norte e Nordeste. Assumem, portanto, prioridade nesse contexto as políticas, programas e projetos que contribuam efetivamente para a redução da pobreza e consequentemente o tão desejável desenvolvimento sustentável.

No Ceará, os programas e projetos desenvolvidos desde 1996, em destaque, Projeto de Combate à Pobreza Rural - PCPR/Projeto São José I e II (apoio a infraestrutura e investimentos sociais e produtivos), evidenciaram resultados de efeito positivo para o combate à pobreza no Estado (Relatórios de Avaliação de Impacto do Projeto). Ao longo dos anos, o Projeto contribuiu para o fortalecimento do capital social como elemento propulsor de um novo processo de desenvolvimento endógeno e suportou a ampliação da infraestrutura social e econômica, com impactos na melhoria da qualidade de vida no meio rural cearense conforme resultados do trabalho realizado por Khan et al. (2005).

Dando continuidade às ações, em 2012, com a assinatura de um Acordo de Empréstimo com o Banco Internacional para Reconstrução e Desenvolvimento - BIRD, o Estado avança na perspectiva do desenvolvimento rural sustentável possibilitando investimentos produtivos para organização de produtores da agricultura familiar com foco na geração de renda no campo e fortalecimento da gestão organizativa. $O$ Projeto de Desenvolvimento Rural Sustentável/Projeto São José III (PDRS/PSJ III) executado entre os anos de 2012 a 2019 apresentou--se como um Projeto cujo foco foi o fortalecimento da agricultura familiar e o bemestar das comunidades rurais. A perspectiva foi de aumentar a inserção econômica, a agregação de valor dos empreendimentos familiares da área rural e o fortalecimento na gestão por meio de financiamento de projetos produtivos no âmbito de diferentes cadeias produtivas.

O PDRS/PSJ III apoia iniciativas produtivas por meio de organizações, sejam elas associações ou cooperativas, mas que tenham como base a agricultura familiar. De acordo com Gameiro et al. (2018), essa é uma forma de envolver as comunidades rurais nos projetos elevando o grau de cooperação no meio rural. Contudo, ao envolver as associações se delega às mesmas as competências necessárias para uma gestão eficiente dos recursos disponibilizados, o que envolve um conjunto de fatores dentre eles mecanismos de gestão social.

A proposta, implícita no PDRS/PSJ III, de incentivar a formação de capital social via elevação na participação em associações e estimular mecanismos de gestão social é compreensível. Desde a última década do século XX, as políticas públicas voltadas para o espaço rural têm criado caminhos institucionais que incentivam a participação dos atores sociais. O tema da participação, em seus múltiplos significados, ganha, assim, importância crescente no debate contemporâneo sobre desenvolvimento. O protagonismo dos atores tem sido colocado como um elemento essencial na perspectiva do desenvolvimento rural e do 
fortalecimento da agricultura familiar, sendo praticamente um consenso nos discursos de gestores públicos, movimentos sociais, entidades não governamentais e organismos internacionais (SANTOS et al., 2016). Veiga et al. (2001) afirmam que os componentes essenciais do processo de desenvolvimento rural são a valorização e o fortalecimento da agricultura familiar, a diversificação econômica, o incentivo e incremento do empreendedorismo local, com o apoio do Estado na formação de arranjos institucionais.

O fortalecimento da gestão social é uma forma de potencializar os resultados das políticas voltadas para o desenvolvimento rural (ANDRADE et al., 2018; VALENCIA et al., 2018). A expressão gestão social, conforme França Filho (2008) tem sido usada de modo corrente nos últimos anos servindo para identificar as mais variadas práticas sociais de diferentes atores não apenas governamentais, mas sobretudo de organizações não-governamentais, associações, fundações, assim como, mais recentemente, algumas iniciativas partindo mesmo do setor privado e que se exprimem nas noções de cidadania corporativa ou de responsabilidade social da empresa.

A gestão social refere-se a um conceito em construção (CANÇADO et al., 2011), com paradigmas ainda por serem definidos (DOWBOR, 2014). Segundo França Filho (2008), apesar da ausência de uma definição única de gestão social, é possível perceber alguns princípios comuns ao conceito, como a postura ética da conduta, a valorização da transparência na gestão dos recursos, bem como a ênfase sobre a democratização das decisões e das relações, indicando a construção de uma nova cultura política que coloca em questão práticas personalistas e clientelistas. O conceito de gestão social de acordo com Cançado et al. (2011) é o da "tomada de decisão coletiva, sem coerção, baseada na inteligibilidade da linguagem, na dialogicidade e no entendimento esclarecido como processo, na transparência como pressuposto e na emancipação enquanto fim último"

O presente artigo objetiva analisar o desempenho das organizações de produtores rurais no Estado do Ceará quanto à implementação de mecanismos de gestão social. Para tanto, optou-se por uma comparação entre organizações de produtores beneficiários e não beneficiários do PDRS. A opção pela análise dos dois grupos foi motivada pelo fato do PDRS ao selecionar organizações de produtores rurais para recebimento de investimento público o faz por meio de uma coletividade (associação) buscando o fortalecimento da agricultura familiar e o bem-estar das comunidades rurais alavancando o desenvolvimento rural local. Contudo, não se tem clareza se tal procedimento tem conseguido promover a gestão social entre seus beneficiários.

\section{METODOLOGIA}

\section{Área de Estudo, Tamanho da amostra e Fonte de dados}

A pesquisa focou sua análise em 52 organizações que manifestaram interesse no projeto, sendo 12 delas beneficiadas e 40 não beneficiadas compreendendo 11 territórios rurais do Estado do Ceará. Para seleção das organizações beneficiadas foi realizado um sorteio. Tendo em vista a realização de uma metodologia aleatorizada foi possível construir dois grupos: Controle (não beneficiários) e Tratados 
(beneficiários). Para medir o nível da gestão social realizou-se uma aplicação de questionário estruturado nos anos 2014 e 2017, que correspondem a anos antes e depois da intervenção do Projeto, respectivamente. Em seguida foi calculado um Índice de Gestão Social - IGP das organizações selecionadas.

\section{Mensuração do Índice de Gestão Social - IGS}

Compreender a dinâmica, ferramentas e processos de gestão das organizações envolvidas no estudo será de fundamental importância para se avaliar como estes fatores interferiram no alcance dos objetivos do PDRS. Nesta pesquisa, a concepção da gestão social foi a da organização social e da ação coletivizada, isto é, a organização de diferentes atores que se encontram imbricados na gestão social (TENÓRIO, 2013).

O IGS agregou diferentes indicadores capazes de captar aspectos distintos do conceito, os quais estão descritos no quadro 1. Os indicadores foram quantificados por meio da atribuição de escores, que obedeceram uma ordem crescente desde a pior até a melhor situação. Os escores atribuídos aos indicadores variaram de zero a 3 (conforme a existência na organização) ou de zero a 1, sendo zero corresponde a respostas negativas e 1 respostas positivas.

Quadro 1: Indicadores selecionados para a mensuração da gestão social das organizações pesquisadas.

\begin{tabular}{|c|c|}
\hline Indicador & $\begin{array}{l}\text { Operacionalização do Indicador (atribuição dos escores) para agregação no Índice } \\
\text { de Gestão Social - IGS }\end{array}$ \\
\hline Participação na gestão da organização & $\begin{array}{l}\text { Quantos membros titulares participam da gestão: } \\
3 \text { - Acima de } 21 \\
2-11 \text { a } 20 \\
1-1 \text { a } 10\end{array}$ \\
\hline $\begin{array}{l}\text { Periodicidade de participação nas } \\
\text { reuniões }\end{array}$ & $\begin{array}{l}\text { Quantas vezes os membros se reúnem: } \\
3 \text { - Uma vez por mês } \\
2 \text { - Cada } 3 \text { meses } \\
1 \text { - Quando for necessário }\end{array}$ \\
\hline $\begin{array}{l}\text { Nível de Instrução do Presidente da } \\
\text { Organização }\end{array}$ & $\begin{array}{l}\text { Qual o grau de escolaridade do presidente da organização: } \\
3 \text { - Ensino Superior } \\
2 \text { - Ensino Fundamental e Médio } \\
1 \text { - Sem escolaridade }\end{array}$ \\
\hline $\begin{array}{l}\text { Participação dos membros na tomada de } \\
\text { decisão da organização }\end{array}$ & $\begin{array}{l}\text { Qual a avaliação da participação dos membros da organização: } \\
\text { 2- Ativa (Muito participativo) } \\
\text { 1- Pouco Participativo }\end{array}$ \\
\hline Prestadores de serviços contratados & $\begin{array}{l}\text { A organização contratou quantos prestadores de serviços: } \\
3-2 \text { (dois prestadores) } \\
2-1 \text { (um prestador) } \\
1-0 \text { (nenhum) }\end{array}$ \\
\hline $\begin{array}{l}\text { Expectativa de aumento do número de } \\
\text { membros da organização }\end{array}$ & $\begin{array}{l}\text { Qual a expectativa para o número de membros da organização para os próximos } \\
\text { dois anos: } \\
\text { 3- Aumentar } \\
\text { 2- Diminuir } \\
1 \text { - Continuar o mesmo }\end{array}$ \\
\hline \multirow[t]{4}{*}{$\begin{array}{l}\text { Apropriação de instrumentos para gestão } \\
\text { da organização }\end{array}$} & $\begin{array}{l}\text { A organização possui Regimento Interno: } \\
0=\text { Não } \\
1=\operatorname{Sim}\end{array}$ \\
\hline & $\begin{array}{l}\text { A organização possui Livro Caixa: } \\
0=\text { Não } \\
1=\operatorname{Sim}\end{array}$ \\
\hline & $\begin{array}{l}\text { A organização possui Balanço Patrimonial: } \\
0=\text { Não } \\
1=\operatorname{Sim}\end{array}$ \\
\hline & $\begin{array}{l}\text { A organização possui Contador: } \\
0=\text { Não } \\
1=\operatorname{Sim}\end{array}$ \\
\hline
\end{tabular}


A agregação de todos os indicadores para compor o IGS, de modo a quantificar o nível de desempenho das organizações foi adaptada de Sousa (2003). Foi utilizada a seguinte expressão matemática:

$$
I G S=\frac{1}{n} \sum_{p=1}^{n}\left[\frac{1}{m} \sum_{j=1}^{m} \frac{E_{j p}}{E_{\max _{j}}}\right]
$$

Em que:

IGS = Índice de Gestão Social; $E_{j p}=$ escore atribuído ao j-ésimo indicador pelo representante da $p$-ésima organização; Emax $_{\mathrm{j}}=$ Escore máximo do j-ésimo indicador; $\mathrm{j}=1, \ldots, \mathrm{m}$, sendo $\mathrm{m}=$ número de indicadores; $p=1, \ldots, n$, sendo $n=$ número de organizações pesquisadas.

O IGS varia entre zero e um, e quanto mais próximo o seu valor se situar de 1 (um), maior é o nível de desempenho da gestão social. De forma oposta, quanto mais próximo o valor do IGS se situar de zero (pior situação), menor é o nível de desempenho avaliado. Para cada indicador analisado foram realizadas análises descritivas dos resultados antes da apresentação do resultado global do índice. Vale ressaltar que nas tabelas de frequências relativas e absolutas, como a quantidade de organizações é diferente entre controle e tratamento, optou-se pelo percentual de cada um dos grupos. Também foram usados testes de hipóteses paramétricos (teste t) e não paramétricos (Mann-Whitney) de acordo com as características dos dados que compõem o citado índice, cuja descrição tem curso em Fávero et al. (2009).

\section{RESULTADOS E DISCUSSÃO}

Os resultados serão abordados em duas etapas, uma análise descritiva e apresentação dos resultados dos testes realizados e posteriormente o resultado global do índice compreendendo os seguintes indicadores: participação na gestão da organização, periodicidade de participação nas reuniões, nível de instrução do presidente da organização, participação dos membros na tomada de decisão da organização, prestadores de serviços contratados, expectativa de aumento do número de membros da organização e apropriação de instrumentos para gestão da organização.

\section{Participação na gestão}

Organizar-se para conquistar seu espaço, para gerir seu próprio destino, para ter vez e voz é o fundamento da organização (DEMO, 2001). A organização deve ser entendida como exercício de cidadania e uma conquista de comunidades organizadas se tornando assim uma peça fundamental de qualquer processo de desenvolvimento.

À medida que a população desenvolve a capacidade de diagnosticar os próprios problemas, 'aumenta a visibilidade social' e com isso são introduzidas 'formas de socialização transversais e solidariedades' que deixam aflorar as necessidades e aspirações da população in loco (ROSANVALLON, 1997). A organização, mais do que acatar deveres e direitos 'decretados', centraria sua força na tomada de decisões e na gestão local, agindo ativamente nos processos de desenvolvimento local. A estratégia da organização permite que as comunidades superem sua condição de sobrevivência e supressões, passando a ser protagonistas de seu 
próprio bem-estar (SAYAGO, 2007).

Para Ferrinho (1978), o papel das associações tem grande importância para o desenvolvimento rural, pois através dessas organizações é possível aos agricultores a organização social na tomada de decisão e organização de mercados. Percebe-se assim, a necessidade do ser humano em se associar em grupos, unindo-se, no esforço de buscar a transformação da realidade.

A organização dos membros na gestão de uma associação representa um aspecto de fundamental importância. Souza (1995) assinala que o processo de gestão participativa envolve um conjunto de ações intencionais, articuladas entre si, cuja origem identifica-se com o próprio interesse em democratizar o processo gestionário. Portanto, deve-se criar instrumentos que possibilitem a todos os membros participarem na gestão das organizações, através da identificação e/ou criação de condições práticas de cooperação/organização, pois "quanto mais as pessoas estiverem envolvidas no poder decisório, haverá maiores informações e mais troca de ideias, o que é bom" (RANDOLPH, 1985).

Conforme tabela 1, o maior percentual de pessoas participando na gestão da organização encontrase na classe de 11 a 20 membros tanto para as organizações beneficiadas como não beneficiadas. Fazendo um comparativo entre controle e tratamento para o ano de 2017, verifica-se que não há diferença significativa entre os grupos quanto à distribuição da quantidade de membros participantes da organização. Ressalta-se que no grupo de tratados, a situação das organizações no ano de 2014 era ainda a de potenciais beneficiários do PDRS/PSJ III.

Tabela 1: Frequência relativa e absoluta de organizações beneficiadas e não beneficiadas do PDRS/PSJ III segundo a participação dos membros na gestão.

\begin{tabular}{|c|c|c|c|c|c|c|c|c|}
\hline \multirow{3}{*}{$\begin{array}{l}\text { Participação } \\
\text { na Gestão }\end{array}$} & \multicolumn{4}{|l|}{ Controle } & \multicolumn{4}{|c|}{ Tratados } \\
\hline & \multicolumn{2}{|l|}{$(2014)$} & \multicolumn{2}{|l|}{ (2017) } & \multicolumn{2}{|c|}{ Potenciais (2014) } & \multicolumn{2}{|l|}{$(2017)$} \\
\hline & $\begin{array}{l}\text { Freq. } \\
\text { Absoluta }\end{array}$ & $\begin{array}{l}\text { Freq. } \\
\text { Relativa }\end{array}$ & $\begin{array}{l}\text { Freq. } \\
\text { Absoluta }\end{array}$ & $\begin{array}{l}\text { Freq. } \\
\text { Relativa }\end{array}$ & $\begin{array}{l}\text { Freq. } \\
\text { Absoluta }\end{array}$ & $\begin{array}{l}\text { Freq. } \\
\text { Relativa }\end{array}$ & $\begin{array}{l}\text { Freq. } \\
\text { Absoluta }\end{array}$ & $\begin{array}{l}\text { Freq. } \\
\text { Relativa }\end{array}$ \\
\hline Acima de 21 membros & 0 & $0 \%$ & 1 & $2,5 \%$ & 0 & $0 \%$ & 0 & $0 \%$ \\
\hline 11 a 20 membros & 27 & $67,5 \%$ & 22 & $55 \%$ & 7 & $58,3 \%$ & 8 & $66,6 \%$ \\
\hline 1 a 10 membros & 13 & $32,5 \%$ & 17 & $42,5 \%$ & 5 & $41,7 \%$ & 4 & $33,4 \%$ \\
\hline Total & 40 & $100 \%$ & 40 & $100 \%$ & 12 & $100 \%$ & 12 & $100 \%$ \\
\hline
\end{tabular}

No caso das organizações beneficiárias, apesar da consciência dos desafios que as organizações iriam enfrentar para a implantação e execução do Projeto, houve um pequeno aumento na quantidade de membros participantes da associação. Para o grupo controle, acredita-se que a não seleção por meio do Projeto poderá ter acarretado desmotivação por parte dos membros.

\section{Periodicidade das reuniões}

Reunião é o momento adequado para discutir problemas comuns, buscar soluções e ideias, definir metas, informar os associados, planejar ações, avaliar os resultados, autorizar e principalmente tomar decisões em grupo. Uma associação deve possibilitar a seus associados ter voz e se fazer ouvir na sociedade e nos espaços de decisão pública. Da mesma forma, para representar os seus interesses seja em políticas e programas governamentais, ou mesmo para obterem acesso a algumas linhas de crédito, os produtores 
rurais necessitam se organizar.

Compartilhar objetivos, buscar soluções trazendo para si a responsabilidade e vivenciar os resultados alcançados fortalecem a autoestima, a autoconfiança e o senso de comunidade. Compreende-se um processo de transformação pessoal, que dá ao produtor rural a oportunidade de vivenciar os resultados da ação individual e coletiva que pode efetivamente transformar o seu contexto de vida.

São nos espaços coletivos de diálogo e decisões, no caso das associações, pode-se considerar também as reuniões e assembleias, que o senso de comunidade, de pertencimento de um projeto coletivo e de bem comum podem se concretizar. Desta forma, acredita-se que quanto maior a oportunidade de promover estes espaços/momentos maior é a possibilidade de vivenciar e perceber como as ações individuais e coletivas colaboram para as transformações da comunidade. Observando a tabela 2, pode-se aferir que tanto nas organizações controle como tratados mais de $75 \%$ se reúnem pelo menos uma vez por mês. Este dado demonstra interesse dos membros em manter um diálogo permanente para discutir as propostas e ações coletivas da comunidade.

Tabela 2: Frequência relativa e absoluta de organizações beneficiadas e não beneficiadas do PDRS/PSJ III segundo a periodicidade de reuniões.

\begin{tabular}{|c|c|c|c|c|c|c|c|c|}
\hline \multirow[t]{3}{*}{ Periodicidade das reuniões } & \multicolumn{4}{|l|}{ Controle } & \multicolumn{4}{|l|}{ Tratados } \\
\hline & \multicolumn{2}{|l|}{$(2014)$} & \multicolumn{2}{|l|}{ (2017) } & \multicolumn{2}{|c|}{ Potenciais (2014) } & \multicolumn{2}{|l|}{ (2017) } \\
\hline & $\begin{array}{l}\text { Freq. } \\
\text { Absoluta }\end{array}$ & $\begin{array}{l}\text { Freq. } \\
\text { Relativa }\end{array}$ & $\begin{array}{l}\text { Freq. } \\
\text { Absoluta }\end{array}$ & $\begin{array}{l}\text { Freq. } \\
\text { Relativa }\end{array}$ & $\begin{array}{l}\text { Freq. } \\
\text { Absoluta }\end{array}$ & $\begin{array}{l}\text { Freq. } \\
\text { Relativa }\end{array}$ & $\begin{array}{l}\text { Freq. } \\
\text { Absoluta }\end{array}$ & $\begin{array}{l}\text { Freq. } \\
\text { Relativa }\end{array}$ \\
\hline Quando necessário & 2 & $5 \%$ & 3 & $7,5 \%$ & 2 & $16,7 \%$ & 1 & $8,3 \%$ \\
\hline Até 1 mês & 30 & $75 \%$ & 32 & $80,0 \%$ & 9 & $75,0 \%$ & 10 & $83,3 \%$ \\
\hline Até 6 meses & 5 & $12,5 \%$ & 5 & $12,5 \%$ & 1 & $8,3 \%$ & 1 & $8,3 \%$ \\
\hline Outros & 3 & $7,5 \%$ & 0 & $0,0 \%$ & 0 & $0,0 \%$ & 0 & $0,0 \%$ \\
\hline Total & 40 & $100 \%$ & 40 & $100 \%$ & 12 & $100 \%$ & 12 & $100 \%$ \\
\hline $\begin{array}{l}\text { Teste U de Mann-Whitney } \\
\text { C17 x T17: O Sig }=0,728\end{array}$ & & & & & & & & \\
\hline
\end{tabular}

Analisando os resultados de 2017 em comparação a 2014 tanto para os grupos controle e tratados, verifica-se que ocorreu um pequeno aumento de organizações que realizam reuniões com uma frequência de até um mês. No caso das beneficiadas, a possibilidade de recursos do PDRS poderá ter proporcionado mais entusiasmo dos membros em contribuir coletivamente para executar a política pública ao passo que no controle, apesar do número de organizações ter aumentado, acredita-se que a motivação seja para ampliar a integração dos membros em busca de outras políticas publicas já que as mesmas não seriam contempladas com aporte financeiro pelo Projeto. O teste U de Mann Whitney para comparação dos dois grupos em 2017 indica que não existe diferença estatisticamente significante em nível de $5 \%$ entre organizações beneficiadas e não beneficiadas quanto à periodicidade de reuniões.

\section{Nível de instrução do presidente}

O grau de escolaridade dos produtores rurais assume importante papel na gestão e organização nos modais da agricultura e pecuária, uma vez que a baixa escolaridade compromete o desenvolvimento sócio territorial, dificulta a compreensão por parte da população nos processos sociopolíticos, facilita a coaptação de atores sociais por grupos políticos dominantes, compromete o grau de reivindicação na melhoria das 
condições de vida, restringe as possibilidades de qualificação profissional e dificulta o uso de mecanismos participativos e da cidadania (BANDEIRA, 2007). A deficiência educacional da maioria dos produtores influencia negativamente nos processos de comercialização, implementação de novos sistemas e ainda reduz a viabilidade frente ao mercado globalizado.

Carvalho (2013) afirmou que muitos produtores rurais possuem dificuldades no momento de utilizar os recursos que sua propriedade possui, pois, grande parte dos mesmos são excluídos educacionalmente, uma vez que a maioria não é alfabetizado ou é considerado analfabeto funcional e ainda, analfabeto digital. Por mais que a propriedade rural seja modesta, é essencial que o produtor saiba gerenciá-la aplicando a função da gestão, que é planejar. Os dados na tabela 3 demonstram que a parcela de presidentes da organização que têm ensino superior é bem ínfima se comparada ao número de organizações que apresentam representantes com nível fundamental e médio.

Tabela 3: Frequência relativa e absoluta de organizações beneficiadas e não beneficiadas do PDRS/PSJ III segundo nível de instrução escolar do presidente.

\begin{tabular}{|c|c|c|c|c|c|c|c|c|}
\hline \multirow{3}{*}{$\begin{array}{l}\text { Nível de instrução do } \\
\text { presidente }\end{array}$} & \multicolumn{4}{|l|}{ Controle } & \multicolumn{4}{|l|}{ Tratados } \\
\hline & \multicolumn{2}{|l|}{$(2014)$} & \multicolumn{2}{|l|}{ (2017) } & \multicolumn{2}{|c|}{ Potenciais (2014) } & \multicolumn{2}{|l|}{$(2017)$} \\
\hline & $\begin{array}{l}\text { Freq. } \\
\text { Absoluta }\end{array}$ & $\begin{array}{l}\text { Freq. } \\
\text { Relativa }\end{array}$ & $\begin{array}{l}\text { Freq. } \\
\text { Absoluta }\end{array}$ & $\begin{array}{l}\text { Freq. } \\
\text { Relativa }\end{array}$ & $\begin{array}{l}\text { Freq. } \\
\text { Absoluta }\end{array}$ & $\begin{array}{l}\text { Freq. } \\
\text { Relativa }\end{array}$ & $\begin{array}{l}\text { Freq. } \\
\text { Absoluta }\end{array}$ & $\begin{array}{l}\text { Freq. } \\
\text { Relativa }\end{array}$ \\
\hline Ensino Fundamental & 17 & $42,5 \%$ & 13 & $32,5 \%$ & 8 & $66,7 \%$ & 8 & $66,7 \%$ \\
\hline Ensino Médio & 15 & $37,5 \%$ & 17 & $42,5 \%$ & 2 & $16,7 \%$ & 2 & $16,7 \%$ \\
\hline Ensino Superior & 7 & $17,5 \%$ & 4 & $10,0 \%$ & 1 & $8,3 \%$ & 1 & $8,3 \%$ \\
\hline Outros & 1 & $2,5 \%$ & 6 & $15,0 \%$ & 1 & $8,3 \%$ & 1 & $8,3 \%$ \\
\hline Total & 40 & $100 \%$ & 40 & $100 \%$ & 12 & $100 \%$ & 12 & $100 \%$ \\
\hline
\end{tabular}

Os dados indicam o predomínio do baixo nível de instrução entre os representantes legais das associações, concentrando nos níveis fundamental e médio. A baixa escolaridade pode ser considerada um fator negativo, pois pode influenciar na capacidade de entendimento e absorção de novos conhecimentos e tecnologias (FERREIRA, 2009).

Comparando o cenário entre os anos de 2014 e 2017 para as organizações beneficiadas, percebe-se que não ocorreram mudanças quanto aos níveis apresentados antes e depois da intervenção. Ao contrário das organizações beneficiadas, nas não beneficiadas ocorreram maiores oscilação de níveis segundo os horizontes temporais avaliados. Houve uma diminuição dos níveis de ensino fundamental e superior gerando um aumento significativo no item 'outros', onde estão situados os não alfabetizados. Essa variação pode ter sido acarretada por mudanças do representante legal da organização (presidente) ao longo do período analisado. Este fator corroborou negativamente às organizações em dois fatores: baixou o nível instrucional do representante legal e pode provocar alterações na dinâmica gerencial da organização, devido a mudança de gestor. $O$ resultado do teste mostra que inexistem diferenças estatisticamente significativas para o nível de instrução dos presidentes das organizações beneficiárias e não beneficiárias do Projeto, ano 2017.

\section{Participação dos membros na tomada de decisão}

Segundo Gandin (2001), a participação pode ser exercida em níveis. O primeiro nível é o da 
colaboração, praticado com maior frequência hoje, em que participantes são chamados para colaborar com ideias, apoio, trabalho, mas o processo serve apenas para legitimar decisões tomadas pelos detentores de poder. O segundo nível é o chamado nível de decisão, em que algumas questões são levadas a grupos, ou as plenárias para que esses decidam. Já o terceiro nível é o chamado de construção em conjunto, é a prática mais rara de se ver em ação. Acontece quando ocorre a participação ampla e ativa dos cidadãos nos processos políticos, sociais ou comunitários e tem como objetivo influenciar as decisões que contemplem os interesses coletivos.

A criação de espaços coletivos e participativos pode ser a porta de acesso da comunidade aos acontecimentos sociais, políticos e econômicos da atualidade e quanto maior a participação mais pessoas se tornam responsáveis pela condução do desenvolvimento da comunidade, ao passo que, a não participação provoca enfraquecimento desses espaços. Os dados da tabela 4 demonstram que o número de organizações que apresentam uma ótima participação dos seus membros na tomada de decisão é bastante expressivo, configurando acima de $80 \%$ para os dois grupos analisados nessa pesquisa.

Tabela 4: Frequência relativa e absoluta de organizações beneficiadas e não beneficiadas do PDRS/PSJ III segundo participação dos membros na tomada de decisão.

\begin{tabular}{|c|c|c|c|c|c|c|c|c|}
\hline \multirow{3}{*}{$\begin{array}{l}\text { Participação } \\
\text { (Tomada de Decisão) }\end{array}$} & \multicolumn{4}{|l|}{ Controle } & \multicolumn{4}{|l|}{ Tratados } \\
\hline & \multicolumn{2}{|l|}{$(2014)$} & \multicolumn{2}{|l|}{ (2017) } & \multicolumn{2}{|c|}{ Potenciais (2014) } & \multicolumn{2}{|l|}{2017} \\
\hline & $\begin{array}{l}\text { Freq. } \\
\text { Absoluta }\end{array}$ & $\begin{array}{l}\text { Freq. } \\
\text { Relativa } \\
\end{array}$ & $\begin{array}{l}\text { Freq. } \\
\text { Absoluta }\end{array}$ & $\begin{array}{l}\text { Freq. } \\
\text { Relativa } \\
\end{array}$ & $\begin{array}{l}\text { Freq. } \\
\text { Absoluta }\end{array}$ & $\begin{array}{l}\text { Freq. } \\
\text { Relativa } \\
\end{array}$ & $\begin{array}{l}\text { Freq. } \\
\text { Absoluta }\end{array}$ & $\begin{array}{l}\text { Freq. } \\
\text { Relativa }\end{array}$ \\
\hline Pouco participativo & 5 & $12,5 \%$ & 7 & $17,5 \%$ & 1 & $8,3 \%$ & 0 & $0,0 \%$ \\
\hline Muito participativo & 35 & $87,5 \%$ & 33 & $82,5 \%$ & 11 & $91,7 \%$ & 12 & $100,0 \%$ \\
\hline Total & 40 & $100 \%$ & 40 & $100 \%$ & 12 & $100 \%$ & 12 & $100 \%$ \\
\hline
\end{tabular}

A participação dos membros na tomada de decisão das ações em prol da comunidade é uma expressão ímpar de comprometimento e responsabilidade pelo desenvolvimento das pessoas e do ambiente onde se vive. No caso das organizações beneficiadas, comparando os anos analisados, houve um pequeno aumento de organizações com maior participação de membros, esse dado por ter sido influenciado pelo fato da organização sentir-se mais estimulada por conta dos recursos aprovados via Projeto. Entretanto, nas organizações não beneficiadas, ocorreu uma pequena diminuição das organizações que detinham maior participação dos seus membros, acredita-se que ao contrário do cenário das beneficiadas, sentiram-se desestimulados pela não seleção. O teste que compara os dois grupos demonstra que a participação na tomada de decisão é estatisticamente igual entre organizações beneficiadas e não beneficiadas pelo PDRS.

\section{Instrumentos de gestão}

Neste tópico, a avaliação descritiva abordou separadamente os seguintes aspectos: Regimento Interno, Livro Caixa, Balanço Patrimonial e Contador. Entretanto, os testes realizados avaliaram o somatório dos quatro itens que compõem o referido indicador. Considerando os documentos da entidade, com relação ao Regimento Interno, por mais que não seja uma exigência legal para uma fundação de uma associação ao contrário do Estatuto, resolveu-se pesquisar sobre este aspecto haja vista que ele traz muito mais elementos 
de como se dará a organização interna de uma associação do que o próprio Estatuto. Não se considera saudável uma associação criar muitas normas no momento da sua fundação, o detalhamento pode ser feito no Regimento cuja vigência precisa somente de uma aprovação da Assembleia Geral.

Adotar o Regimento Interno pode demonstrar uma melhor cultura organizacional. De acordo com Raskin (2002) a estrutura organizacional é o sistema formal de tarefas, relacionamentos e formas de motivação, a qual determina como as pessoas coordenam suas ações e utilizam os recursos para atingir os objetivos organizacionais. A Cultura Organizacional é o conjunto de valores compartilhados e normas que controlam a interação entre os membros da organização.

Na tabela 5 se verifica que há maior número de organizações tanto no grupo controle quanto nos tratados que têm o Regimento Interno como documento que rege as normas internas de condução dos membros em prol do desenvolvimento e gestão da organização. Entretanto, vale ressaltar que ao longo do período avaliado houve acréscimo de organizações que informaram não possuir mais o regimento. Sobre este aspecto, salienta-se que, o 'não possuir' no ano de 2017 mesmo tendo informado em 2014 que possuía, trata-se de uma possível falta de revisão/atualização passando a ser um documento obsoleto.

Tabela 5: Frequência relativa e absoluta de organizações beneficiadas e não beneficiadas do PDRS/PSJ III que possui Regimento interno.

\begin{tabular}{|l|l|l|l|l|l|l|l|l|}
\hline \multirow{3}{*}{ Regime Interno } & \multicolumn{4}{|l|}{ Controle } & \multicolumn{2}{l|}{ Tratados } \\
\cline { 2 - 9 } & $\mathbf{( 2 0 1 4 )}$ & $\mathbf{1 2 0 1 7 )}$ & Potenciais (2014) & (2017) \\
\cline { 2 - 9 } & $\begin{array}{l}\text { Freq. } \\
\text { Absoluta }\end{array}$ & $\begin{array}{l}\text { Freq. } \\
\text { Relativa }\end{array}$ & $\begin{array}{l}\text { Freq. } \\
\text { Absoluta }\end{array}$ & $\begin{array}{l}\text { Freq. } \\
\text { Relativa }\end{array}$ & $\begin{array}{l}\text { Freq. } \\
\text { Absoluta }\end{array}$ & $\begin{array}{l}\text { Freq. } \\
\text { Relativa }\end{array}$ & $\begin{array}{l}\text { Freq. } \\
\text { Absoluta }\end{array}$ & $\begin{array}{l}\text { Freq. } \\
\text { Relativa }\end{array}$ \\
\hline Sim & 30 & $75 \%$ & 23 & $57,5 \%$ & 7 & $58,53 \%$ & 6 & $50,0 \%$ \\
\hline Não & 10 & $25 \%$ & 17 & $42,5 \%$ & 5 & $41,7 \%$ & 6 & $50,0 \%$ \\
\hline Total & $\mathbf{4 0}$ & $\mathbf{1 0 0} \%$ & $\mathbf{4 0}$ & $\mathbf{1 0 0} \%$ & $\mathbf{1 2}$ & $\mathbf{1 0 0} \%$ & $\mathbf{1 2}$ & $\mathbf{1 0 0 \%}$ \\
\hline
\end{tabular}

Uma importante ferramenta de gestão nas entidades sem fins lucrativos é a prestação de contas. Os relatórios, de administração e contábeis, são compostos de dados históricos da instituição, no qual são evidenciados a missão e objetivos, evolução das atividades desenvolvidas, planejamento da gestão, demonstrações contábeis, dentre outros. Neste sentido, a transparência, os relatórios de avaliação e os instrumentos de comunicação caracterizam uma forma de controle gerencial por essas entidades (OLAK et al., 2006).

As associações devem ser administradas de forma coerente, e neste sentido a Contabilidade é vista como ferramenta que visa demonstrar a origem e a forma como foram aplicados os recursos, evidenciando a transparência da prestação de contas para a sociedade, bem como o controle nos aspectos contábeis e administrativos (VOLTOLINI, 2004).

A atuação do contador na área burocrática de regularização da documentação das associações influencia diretamente numa gestão mais eficiente e transparente. Na tabela 6, pode-se observar que ao longo do período analisado houve uma maior preocupação por parte das organizações em obter um profissional contador para realizar os controles contábeis e administrativos. Nas organizações controle, em $2017,75 \%$ possuem contador e nas beneficiadas, $83 \%$ disseram possuir o profissional. 
Tabela 6: Frequência relativa e absoluta de organizações beneficiadas e não beneficiadas do PDRS/PSJ III que possui Contador.

\begin{tabular}{|l|l|l|l|l|l|l|l|l|}
\hline \multirow{3}{*}{ Contador } & \multicolumn{9}{|l|}{ Controle } & \multicolumn{2}{|l|}{ Tratados } \\
\cline { 2 - 9 } & $\mathbf{( 2 0 1 4 )}$ & $\mathbf{( 2 0 1 7 )}$ & Potenciais (2014) & (2017) \\
\cline { 2 - 9 } & $\begin{array}{l}\text { Freq. } \\
\text { Absoluta }\end{array}$ & $\begin{array}{l}\text { Freq. } \\
\text { Relativa }\end{array}$ & $\begin{array}{l}\text { Freq. } \\
\text { Absoluta }\end{array}$ & $\begin{array}{l}\text { Freq. } \\
\text { Relativa }\end{array}$ & $\begin{array}{l}\text { Freq. } \\
\text { Absoluta }\end{array}$ & $\begin{array}{l}\text { Freq. } \\
\text { Relativa }\end{array}$ & $\begin{array}{l}\text { Freq. } \\
\text { Absoluta }\end{array}$ & $\begin{array}{l}\text { Freq. } \\
\text { Relativa }\end{array}$ \\
\hline Sim & 17 & $42,5 \%$ & 30 & $75,0 \%$ & 6 & $50,0 \%$ & 10 & $83,3 \%$ \\
\hline Não & 23 & $57,5 \%$ & 10 & $25,0 \%$ & 6 & $50,0 \%$ & 2 & $16,7 \%$ \\
\hline Total & $\mathbf{4 0}$ & $\mathbf{1 0 0} \%$ & $\mathbf{4 0}$ & $\mathbf{1 0 0 \%}$ & $\mathbf{1 2}$ & $\mathbf{1 0 0 \%}$ & $\mathbf{1 2}$ & $\mathbf{1 0 0 \%}$ \\
\hline
\end{tabular}

Duas ferramentas importantes para gestão contábil da organização são: livro caixa e balanço patrimonial. No livro Caixa são registrados todos os recebimentos e pagamentos em dinheiro, lançados de forma cronológica (dia, mês e ano), ou seja, destina-se ao controle dos lançamentos exclusivos de entrada e saída. Na tabela 7, percebe-se que os maiores percentuais nos dois grupos estudados se referem a resposta sim, as organizações em sua maioria possuem o livro caixa. Entretanto, constata-se que ocorreu um aumento significativo de organizações não beneficiadas que informaram possuir livro caixa em 2017, ao passo que nas organizações beneficiadas esta prática deixou de existir. Esses dados podem refletir que, nas organizações não beneficiadas ocorreu uma maior preocupação em organizar o controle contábil com vistas ao acesso por outras políticas públicas.

Tabela 7: Frequência relativa e absoluta de organizações beneficiadas e não beneficiadas do PDRS/PSJ III que possui Livro caixa.

\begin{tabular}{|l|l|l|l|l|l|l|l|l|}
\hline \multirow{3}{*}{ Livro Caixa } & \multicolumn{4}{|l|}{ Controle } & \multicolumn{2}{l|}{ Tratados } \\
\cline { 2 - 9 } & $\mathbf{( 2 0 1 4 )}$ & $\mathbf{( 2 0 1 7 )}$ & Potenciais (2014) & (2017) \\
\cline { 2 - 9 } & $\begin{array}{l}\text { Freq. } \\
\text { Absoluta }\end{array}$ & $\begin{array}{l}\text { Freq. } \\
\text { Relativa }\end{array}$ & $\begin{array}{l}\text { Freq. } \\
\text { Absoluta }\end{array}$ & $\begin{array}{l}\text { Freq. } \\
\text { Relativa }\end{array}$ & $\begin{array}{l}\text { Freq. } \\
\text { Absoluta }\end{array}$ & $\begin{array}{l}\text { Freq. } \\
\text { Relativa }\end{array}$ & $\begin{array}{l}\text { Freq. } \\
\text { Absoluta }\end{array}$ & $\begin{array}{l}\text { Freq. } \\
\text { Relativa }\end{array}$ \\
\hline Sim & 27 & $67,5 \%$ & 34 & $85,0 \%$ & 10 & $83,3 \%$ & 7 & $58,3 \%$ \\
\hline Não & 13 & $32,5 \%$ & 6 & $15,0 \%$ & 2 & $16,7 \%$ & 5 & $41,7 \%$ \\
\hline Total & $\mathbf{4 0}$ & $\mathbf{1 0 0 \%}$ & $\mathbf{4 0}$ & $\mathbf{1 0 0 \%}$ & $\mathbf{1 2}$ & $\mathbf{1 0 0 \%}$ & $\mathbf{1 2}$ & $\mathbf{1 0 0 \%}$ \\
\hline
\end{tabular}

A outra ferramenta, balanço patrimonial, consiste num relatório contábil que demonstra a posição financeira e econômica da organização. Essa demonstração informa toda a situação patrimonial, ou seja, os bens, direitos e obrigações da organização. Além disso, é possível identificar todos os investimentos e suas fontes de recursos.

Tabela 8: Frequência relativa e absoluta de organizações beneficiadas e não beneficiadas do PDRS/PSJ III que possui balanço patrimonial.

\begin{tabular}{|l|l|l|l|l|l|l|l|l|}
\hline \multirow{3}{*}{ Balanço Patrimonial } & \multicolumn{2}{|l|}{ Controle } & \multicolumn{3}{l|}{ Tratados } \\
\cline { 2 - 9 } & $\mathbf{( 2 0 1 4 )}$ & $\mathbf{( 2 0 1 7 )}$ & Potenciais (2014) & (2017) \\
\cline { 2 - 9 } & $\begin{array}{l}\text { Freq. } \\
\text { Absoluta }\end{array}$ & $\begin{array}{l}\text { Freq. } \\
\text { Relativa }\end{array}$ & $\begin{array}{l}\text { Freq. } \\
\text { Absoluta }\end{array}$ & $\begin{array}{l}\text { Freq. } \\
\text { Relativa }\end{array}$ & $\begin{array}{l}\text { Freq. } \\
\text { Absoluta }\end{array}$ & $\begin{array}{l}\text { Freq. } \\
\text { Relativa }\end{array}$ & $\begin{array}{l}\text { Freq. } \\
\text { Absoluta }\end{array}$ & $\begin{array}{l}\text { Freq. } \\
\text { Relativa }\end{array}$ \\
\hline Sim & 28 & $70 \%$ & 33 & $82,5 \%$ & 11 & $91,7 \%$ & 10 & $83,3 \%$ \\
\hline Não & 12 & $30 \%$ & 7 & $17,5 \%$ & 1 & $8,3 \%$ & 2 & $16,7 \%$ \\
\hline Total & $\mathbf{4 0}$ & $\mathbf{1 0 0 \%}$ & $\mathbf{4 0}$ & $\mathbf{1 0 0} \%$ & $\mathbf{1 2}$ & $\mathbf{1 0 0 \%}$ & $\mathbf{1 2}$ & $\mathbf{1 0 0 \%}$ \\
\hline
\end{tabular}

Assim como no livro caixa, conforme tabela 8 predomina o número de organizações que possuem balanço patrimonial tanto para as beneficiadas como não beneficiadas. 0 mesmo cenário constatado para 0 livro caixa ocorreu para o balanço patrimonial, ou seja, aumento no número de organizações que informaram possuir a ferramenta em 2017 comparado a 2014 no grupo controle ao passo que no grupo tratados, houve uma redução. 
Do total de 40 organizações não beneficiadas, em 2014, 25\% delas afirmaram possuir todos os instrumentos de gestão abordados neste tópico enquanto em 2017, passou a ser um total de $40 \%$. Para o grupo das beneficiadas, num total de 12 organizações, 41,6\% afirmaram possuir os quatro instrumentos em 2014. Já em 2017, o percentual caiu para 16,6\%. Os dados demonstram que as organizações não beneficiárias demonstram mais interesse em organizar a sua gestão em prol de ter maiores oportunidades de acessar outras políticas públicas.

\section{Prestadores de serviços contratados}

Na atualidade, devido à complexidade da agricultura moderna, exige-se das organizações de produtores rurais um conjunto de expertise se tornando indispensável o apoio de serviços especializados com intuito de prestar assistência em questões de ordem econômica, administrativa, contábil, jurídica, ambiental, entre outras.

Alguns destes tipos de serviços, entretanto, não têm sido priorizados pelas entidades públicas de assistência técnica e extensão rural, levando as organizações a direcionarem sua demanda aos técnicos da iniciativa privada. De acordo com a tabela 9, tanto para organizações beneficiárias quanto não beneficiárias prevalecem aquelas que não contratam nenhum tipo de prestadores de serviços seja para questões de gestão (contábil, administrativa) ou mesmo para fins de apoio à produção dos membros.

Tabela 9: Frequência relativa e absoluta de organizações beneficiadas e não beneficiadas do PDRS/PSJ III segundo a quantidade de prestadores de serviços contratados.

\begin{tabular}{|c|c|c|c|c|c|c|c|c|}
\hline \multirow{3}{*}{$\begin{array}{l}\text { Prestadores de serviços } \\
\text { contratados }\end{array}$} & \multicolumn{4}{|l|}{ Controle } & \multicolumn{4}{|l|}{ Tratados } \\
\hline & \multicolumn{2}{|l|}{$(2014)$} & \multicolumn{2}{|l|}{ (2017) } & \multicolumn{2}{|c|}{ Potenciais (2014) } & \multicolumn{2}{|l|}{$(2017)$} \\
\hline & $\begin{array}{l}\text { Freq. } \\
\text { Absoluta }\end{array}$ & $\begin{array}{l}\text { Freq. } \\
\text { Relativa }\end{array}$ & $\begin{array}{l}\text { Freq. } \\
\text { Absoluta }\end{array}$ & $\begin{array}{l}\text { Freq. } \\
\text { Relativa }\end{array}$ & $\begin{array}{l}\text { Freq. } \\
\text { Absoluta }\end{array}$ & $\begin{array}{l}\text { Freq. } \\
\text { Relativa }\end{array}$ & $\begin{array}{l}\text { Freq. } \\
\text { Absoluta }\end{array}$ & $\begin{array}{l}\text { Freq. } \\
\text { Relativa }\end{array}$ \\
\hline 0 & 32 & $80,0 \%$ & 29 & $72,5 \%$ & 8 & $66,7 \%$ & 7 & $58,3 \%$ \\
\hline 1 & 8 & $20,0 \%$ & 10 & $25,0 \%$ & 4 & $33,7 \%$ & 5 & $41,7 \%$ \\
\hline 2 & 0 & $0,0 \%$ & 1 & $2,5 \%$ & 0 & $0,0 \%$ & 0 & $0,0 \%$ \\
\hline Total & 40 & $100 \%$ & 40 & $100 \%$ & 12 & $100 \%$ & 12 & $100 \%$ \\
\hline
\end{tabular}

Pelos dados apresentados, tanto nas organizações controle quanto tratados predominam a utilização da mão de obra dos próprios membros. No grupo controle, comparando os dados de 2017 com os de 2014 ocorreu uma maior procura por prestadores de serviços do que no grupo beneficiado. Estes números refletem, por exemplo, a presença de profissionais da contabilidade nas organizações bem como outras atividades mais pontuais de operadores de máquinas, dentre outros. Esta maior dinamização no grupo controle reafirma a necessidade destas organizações aperfeiçoarem sua gestão com objetivo de buscar acessos a créditos. Os dados no geral refletem a baixa tradição das organizações de produtores rurais em contratar serviços regulares de assessoria. O teste $U$ de Mann-Whitney demonstra que a contratação de prestadores de serviços é estatisticamente igual entre organizações beneficiadas e não beneficiadas do PDRS, considerando-se o ano de 2017. 


\section{Expectativa em relação ao número de associados}

A legislação não estabelece um número mínimo para se organizar uma associação, em princípio bastariam duas pessoas. Na prática, porém, esse número mínimo seria de dez pessoas, pois é o número necessário para preencher os cargos do Conselho de Administração e Conselho Fiscal que o Novo Código Civil $^{1}$ exige que sejam formados. Conforme tabela 10 se verifica que mais de $70 \%$ das organizações beneficiadas e não beneficiadas informaram ter interesse em aumentar o número de membros.

Tabela 10: Frequência relativa e absoluta de organizações beneficiadas e não beneficiadas do PDRS/PSJ III segundo expectativa em relação ao número de associados.

\begin{tabular}{|c|c|c|c|c|c|c|c|c|}
\hline \multirow{3}{*}{$\begin{array}{l}\text { Expectativa } \\
\text { de associados }\end{array}$} & \multicolumn{4}{|l|}{ Controle } & \multicolumn{4}{|c|}{ Tratados } \\
\hline & \multicolumn{2}{|l|}{ (2014) } & \multicolumn{2}{|l|}{ (2017) } & \multicolumn{2}{|c|}{ Potenciais (2014) } & \multicolumn{2}{|l|}{ (2017) } \\
\hline & $\begin{array}{l}\text { Freq. } \\
\text { Absoluta }\end{array}$ & $\begin{array}{l}\text { Freq. } \\
\text { Relativa }\end{array}$ & $\begin{array}{l}\text { Freq. } \\
\text { Absoluta }\end{array}$ & $\begin{array}{l}\text { Freq. } \\
\text { Relativa }\end{array}$ & $\begin{array}{l}\text { Freq. } \\
\text { Absoluta }\end{array}$ & $\begin{array}{l}\text { Freq. } \\
\text { Relativa }\end{array}$ & $\begin{array}{l}\text { Freq. } \\
\text { Absoluta }\end{array}$ & $\begin{array}{l}\text { Freq. } \\
\text { Relativa }\end{array}$ \\
\hline Continuar o mesmo & 12 & $29,3 \%$ & 9 & $22,5 \%$ & 1 & $8,3 \%$ & 2 & $16,7 \%$ \\
\hline Aumentar & 27 & $68,3 \%$ & 31 & $77,5 \%$ & 11 & $91,7 \%$ & 10 & $83,3 \%$ \\
\hline Diminuir & 1 & $2,4 \%$ & 0 & $0,0 \%$ & 0 & $0,0 \%$ & 0 & $0,0 \%$ \\
\hline Total & 40 & $100 \%$ & 40 & $100 \%$ & 12 & $100 \%$ & 12 & $100 \%$ \\
\hline
\end{tabular}

Importante salientar que, quando não se tem um arcabouço organizacional estruturado, um aumento do número de associados pode provocar um menor monitoramento entre os membros e, nesse caso, uma menor participação gera também um menor compromisso relacional entre a organização e os seus associados.

No caso do grupo controle, entre 2014 e 2017, houve um acréscimo de 9,2\% de organizações que tiveram interesse em aumentar seu número de sócios. No grupo de organizações beneficiadas, ocorreu uma redução de $8,4 \%$. Contudo, o resultado do teste para comparação dos dois grupos no ano mais recente (2017) mostra que inexistem diferenças significativas quanto à expectativa em relação ao número de associados entre organizações beneficiadas e não beneficiadas do Projeto.

\section{Resultado Global do Índice de Gestão Social}

O nível de gestão social das organizações agrega todos os indicadores analisados nas subseções anteriores. Assim, a agregação dos mesmos resultou no que foi denominado aqui de Índice de Gestão Social (IGS). Os valores adotados na mensuração do índice variam de zero a um, sendo quanto mais próximo o seu valor se situar de 1 (um), maior é o nível de gestão social. Verifica-se na tabela 11 que tanto as organizações beneficiadas quanto as não beneficiadas encontram-se um pouco superior à média de 0,5.

Nos dois grupos, os indicadores que obtiveram resultados abaixo da média implicando de forma direta no dado global foram: nível de instrução do presidente e prestadores de serviços contratados. Participação da tomada de decisão e expectativa em aumentar o número de membros foram os indicadores que mais alavancaram o resultado global do índice.

\footnotetext{
${ }^{1}$ Novo Código Civil Lei n. 10.406 de 2002. 
Tabela 11: Resultado Global do Índice.

\begin{tabular}{|l|l|l|l|l|l|l|l|}
\hline Indicadores & \multicolumn{2}{|l|}{ Controle } & \multicolumn{2}{l|}{ Tratados } & Controle x tratados (ano 2017) \\
\cline { 2 - 8 } & $\mathbf{( 2 0 1 4 )}$ & $\mathbf{( 2 0 1 7 )}$ & $\begin{array}{l}\text { Valor } \\
\text { de } \mathbf{P}^{*}\end{array}$ & Potências (2014) & $\mathbf{( 2 0 1 7 )}$ & $\begin{array}{l}\text { Valor } \\
\text { de } \mathbf{P}^{*}\end{array}$ & Valor de $\mathbf{P}^{* *}$ \\
\hline Participação na gestão & 0,55 & 0,53 & 0,660 & 0,53 & 0,56 & 0,339 & 0,650 \\
\hline $\begin{array}{l}\text { Periodicidade de } \\
\text { reuniões }\end{array}$ & 0,72 & 0,74 & 0,584 & 0,65 & 0,75 & 0,137 & 0,728 \\
\hline $\begin{array}{l}\text { Nível de Instrução do } \\
\text { Presidente }\end{array}$ & 0,54 & 0,49 & 0,480 & 0,42 & 0,42 & 1,000 & 0,309 \\
\hline $\begin{array}{l}\text { Participação na tomada } \\
\text { de decisão }\end{array}$ & 0,94 & 0,89 & 0,253 & 0,96 & 0,92 & 0,339 & 0,667 \\
\hline Instrumentos de gestão & 0,64 & 0,75 & 0,054 & 0,71 & 0,69 & 0,866 & 0,333 \\
\hline $\begin{array}{l}\text { Prestadores de serviços } \\
\text { contratados }\end{array}$ & 0,11 & 0,15 & 0,474 & 0,17 & 0,21 & 0,586 & 0,394 \\
\hline $\begin{array}{l}\text { Expectativa de aumento } \\
\text { do número de membros }\end{array}$ & 0,88 & 0,93 & 0,256 & 0,97 & 0,94 & 0,339 & 0,667 \\
\hline Resultado Global & $\mathbf{0 , 6 3}$ & $\mathbf{0 , 6 4}$ & 0,540 & $\mathbf{0 , 6 3}$ & $\mathbf{0 , 6 4}$ & 0,735 & 0,819 \\
\hline
\end{tabular}

* Valor de $\mathrm{P}$ correspondente ao teste ' $\mathrm{t}$ ' de Student para dados pareados (comparação de controle nos anos 2014 e 2017 e de tratados nos anos 2014 e 2017)

** Valor de P correspondente ao teste U de Mann-Whitney (comparação de controle x tratados no ano de 2017).

As comparações temporais e entre grupos, por meio de testes estatísticos, mostrou que o nível de gestão social das organizações não se alterou entre os anos 2014 e 2017, nem entre organizações beneficiadas pelo projeto, nem entre as não beneficiadas. Comparando-se os dois grupos no ano 2017, também não há diferença significativa. Esse resultado sugere que o desempenho das organizações quanto à gestão social é relativamente baixo e não tem evoluído com o tempo. Outro ponto a destacar é a inoperância do PDRS/PSJ III no sentido de mudar esse cenário.

Os resultados demonstram que ainda há grande necessidade de se fortalecer a gestão das organizações do meio rural cearense. A falta de uma gestão ágil e participativa com instrumentos que promovam uma maior organização tornam os processos de operacionalização de políticas públicas ainda mais desafiadores.

\section{CONCLUSÕES}

A metodologia abordada nesta pesquisa (ter um contra factual para nível de comparação) permitiu não somente analisar o desempenho das organizações beneficiadas, mas também compará-las com as não beneficiadas. Para os indicadores selecionados no 'Índice de Gestão Social' foi possível identificar nas organizações beneficiadas o seguinte desempenho: tendência de aumento dos membros titulares participando da gestão; uma participação mais ativa dos membros nas reuniões para tomadas de decisão tornando os espaços mais participativos e atuantes, bem como tendência no aumento (periodicidade) destes espaços de diálogos e com boas expectativas de aumentar ainda mais o número de membros. Contudo, tratase apenas de uma tendência, sem que tenha ocorrido mudança estatisticamente significativa.

No caso das organizações não beneficiadas, os indicadores que tiveram desempenho positivo foram: maior número de organizações que decidiu se reunir mais vezes indicando que há uma preocupação aparente com as decisões coletivas bem como contratação de profissionais com vistas a melhoraria dos controles administrativos/financeiro/contábil. Similarmente, não se trata de alteração estatisticamente significativa.

Os testes realizados no decorrer da pesquisa provaram que estatisticamente os grupos comparados 
são iguais demonstrando que, por mais que algumas organizações tenham recebido apoio do Projeto para fortalecimento da sua gestão e apoio a produção/comercialização, de fato, esse aspecto não corroborou para um bom desempenho na gestão. Outro detalhe que deve ser ressaltado é que o nível de gestão apresentado em 2014 pelas organizações já demonstrava certas fragilidades e como não ocorreu avanços significativos no desempenho em 2017, foram desencadeados sucessivos atrasos nos repasses de recursos para as organizações tardando sobremaneira a execução da política pública ora abordada.

Algumas reflexões precisam ser abordadas: o melhor caminho para promover o desenvolvimento rural seria somente por meio de uma organização formalizada? Ou sendo desta forma, deveriam ser buscados instrumentos para uma melhor seleção dos perfis de organização que detém uma gestão social mais qualificada?. E por último, mas não para concluir a análise, sugere-se uma nova pesquisa para coletar os dados de 2019 e mensurar novamente o desempenho das organizações após a finalização do Projeto.

\section{REFERÊNCIAS}

BANDEIRA, D. A.; CASTRO, R. S.; AZEVEDO, E. O.; MELO, L. S. S.; MELO, C. B.. Características de produção da caprinocultura leiteira na região do Cariri na Paraíba. Ciência Veterinária nos Trópicos, Recife, v.10, n.1, p.29-35, 2007.

CANÇADO, A.; TENÓRIO, F. G.; PEREIRA, J. R.. Gestão social: reflexões teóricas e conceituais. Caderno EBAPE, Rio de Janeiro, v.9, n.3, p.681-703, 2011.

CARVALHO, F. A.. Inclusão digital: a influência do ensino de informática como contribuição á gestão rural e familiar. Repositório institucional. Porto Velho: UNIR, 2013.

DEMO, P.. Participação é Conquista: Noções de política social participativa. São Paulo: Cortez. 2001.

DOWBOR, L.. Gestão Social e transformação da sociedade. 2014.

FÁVERO, L. P.; BELFIORE, P.; SILVA, F. D.; CHAN, B. L.. Análise de dados: Modelagem multivariada para tomada de decisões. Rio de Janeiro: Campus, 2009.

FERREIRA, V. S.. O impacto do Programa Agente Rural sobre o nível tecnológico, geração de emprego e renda e qualidade de vida das famílias assistidas do Estado do Ceará. Dissertação (Mestrado em Economia Rural) Universidade Federal do Ceará, Fortaleza, 2009.

FERRINHO, H.. Cooperativas e desenvolvimento rural. Clássica, 1978.

FRANÇA FILHO, G. C.. Definido gestão social. In: SILVA JÚNIOR, J. T.; MÂISH, R. T.; CANÇADO, A. C.. Gestão social: práticas em debate, teorias em construção. Fortaleza: UFCE, 2008. p.27-38.

GAMEIRO, M. B. P.; MARTINS, R. C.. O desenvolvimento rural sob regime de verdade: o discurso do Banco Mundial.

Sociedade e Estado, v.33, n.1, p.13-37, 2018.

GANDIN, D.. A posição do Planejamento Participativo entre as Ferramentas de Intervenção na Realidade. Currículo Sem Fronteiras, v.1, n.1, p.81-95, 2001.
KHAN, A. S.; SILVA, L. M. R.. Capital Social das Comunidades Beneficiadas pelo Programa de Combate à Pobreza Rural PCPR/Projeto São José - PSJ - Estado do Ceará. Rev. Econ. Sociol. Rural, Rio de Janeiro, v.43, n.1, 2005.

OLAK, P. A.; NASCIMENTO, D. T.. Contabilidade para entidades sem fins lucrativos (Terceiro Setor). São Paulo: Atlas, 2006.

RANDOLPH, L.. Democracia e participação. Brasília: Universidade de Brasília, 1985.

RASKIN, S. F.. As Organizações e a Teoria Organizacional. 2002.

ROSANVALLON, P.. A crise do Estado-providência. Goiânia: UFG, 1997.

SANTOS, J. C.; MENDES, M. A.. Gestão social como uma forma de empoderamento: alguns desafios para a democratização de políticas públicas para o meio rural. In: A construção do Brasil: geografia, ação política e democracia. São Luís, 2016.

SAYAGO, D.. Os Conselhos de Desenvolvimento Territorial: entre a participação e a representação. G\&DR, Taubaté, v.3, n.4, p.9-21, 2007.

ANDRADE, L. F. S.; ALCÂNTRA, V. C.; PEREIRA, F. R.; PEREIRA, J. R.. Espaço, território e lugar: revisão da literatura dos estudos em gestão social sobre formação sócio-espacial. Amazônia, Organizações e Sustentabilidade, v.7, n.2, 2018.

SOUSA, M. C.. Estudo da sustentabilidade da agricultura familiar em assentamentos de reforma agrária no município de Mossoró-RN. Dissertação (Mestrado em Desenvolvimento e Meio Ambiente) - Universidade do Estado do Rio Grande do Norte, Natal, 2003.

SOUZA, M. L. O.. Participação em Associação de Pequenos Produtores: Dilema da Administração Coletiva. Lavras: UFLA, 1995. 
TENÓRIO, F. F.. Verbete Gestão Social. In: GIOVANNI, G. E.; NOGUEIRA, M. A.. Dicionário de políticas públicas. São Paulo: Fundap, 2013.

VALENCIA, M.; SABOURIN, E. P.; BALESTRO, M.; SAYAGO, D.. Programa de desenvolvimento sustentável de territórios rurais no Brasil. In: SABOURIN, E.; GRISA, C.. A difusão de políticas brasileiras para a agricultura familiar na América Latina. Porto Alegre: Escritos, 2018.
VEIGA, J. E.; FAVARETO, A.; AZEVEDO, C. M. A.;

BITTENCOURT, G.; VECCHIATTI, K.; MAGALHÃES, R.; JORGE, R.. O Brasil rural precisa de uma estratégia de desenvolvimento. Brasília: Convênio FIPE - IICA (MDA/CNDRS/NEAD), 2001.

VOLTOLINI, R.. Terceiro Setor: Planejamento \& Gestão. São Paulo: SENAC, 2004.

A CBPC - Companhia Brasileira de Produção Científica (CNPJ: 11.221.422/0001-03) detém os direitos materiais desta publicação. Os direitos referem-se à publicação do trabalho em qualquer parte do mundo, incluindo os direitos às renovações, expansões e disseminações da contribuição, bem como outros direitos subsidiários. Todos os trabalhos publicados eletronicamente poderão posteriormente ser publicados em coletâneas impressas sob coordenação da Sustenere Publishing, da Companhia Brasileira de Produção Científica e seus parceiros autorizados. Os (as) autores (as) preservam os direitos autorais, mas não têm permissão para a publicação da contribuição em outro meio, impresso ou digital, em português ou em tradução. 